\title{
Stress Corrosion Studies of Titanium Dioxide Particulate Reinforced ZA-27 Metal Matrix Composites
}

\author{
K. Vinutha \\ Associate Professor \\ Department of Chemistry, \\ East West Institute of Technology, \\ Bangalore, Karnataka, India
}

\author{
P. V. Krupakara \\ Vice Principal and Professor \\ Department of Chemistry, \\ Cambridge Institute of \\ Technology-North Campus, \\ Bangalore, Karnataka, India
}

\author{
H. R. Radha \\ Professor \\ Department of Chemistry, \\ T. John Institute of Technology, \\ Bangalore, Karnataka, India
}

\begin{abstract}
The stress corrosion resistance of $\mathrm{ZA}-27$ / TiO2 metal matrix composites (MMC's) in high temperature acidic media has been evaluated using an autoclave. The liquid melt metallurgy technique using vortex method was used to fabricate MMC's. TiO2 particulates of $50-80 \mu \mathrm{m}$ in size are added to the matrix. ZA-27 containing 2, 4, 6 weight percentage of $\mathrm{TiO} 2$ are prepared. Stress corrosion tests were conducted by weight loss method for different exposure time, normality and temperature of the acidic medium. The corrosion rates of composites were lower to that of matrix ZA-27 alloy under all conditions.
\end{abstract}

Keywords: Autoclave MMC's, Stress corrosion, Vortex.

\section{INTRODUCTION}

METAL matrix composites (MMCs) made of ZA-27 offer the designer with many added benefits, since they are particularly suitable for application requiring their combined high strength [1]. Better wear resistance [2], thermal conductivity [3], damping properties [4], and low coefficient of thermal expansion with lower density [5]. These properties of MMCs enhance their usage in automotive and tribological applications. The trend is towards safe usage of MMC parts in the automobile engine, which works particularly at high temperature and pressure environments [6]-[7]. Particle reinforced MMC's has been the most popular over the last two decades. Among them ceramic reinforced ZA-27 are very popular in the recent days. The addition of the ceramic particle will not only enhance the mechanical and physical properties, but also change the corrosion properties significantly.
Particle reinforced ZA MMC's find number of applications in several thermal environments especially in the automobile engine parts such as brake drum, brake rotors, cylinders and pistons. MMC's used at high thermal conditions should have good mechanical properties and resistance chemical attack in air and acidic environment. It is necessary that the detail corrosion behaviour of ZA composites must be understood thoroughly for high temperature applications. Several authors [8]-[10] point out that the extent of pitting in SiC-ZA-27 MMC increased with increase in $\mathrm{SiC}$ volume fraction which may be due to the preferential acidic attack at the matrix reinforcement interface[11]. The corrosion behaviour of MMCs is influenced by the nature of matrix alloy, type of reinforcement and alloying elements [12][13]. The objective of the present investigation is to understand the role of reinforcement on the stress corrosion behaviour of ZA-27/titanium dioxide MMCs at high temperature in varied normalities of Hydrochloric acid solutions. High temperature and pressure in an autoclave is an excellent test for stress corrosion.

To insert images in Word, position the cursor at the insertion point and either use Insert | Picture | From File or copy the image to the Windows clipboard and then Edit | Paste Special | Picture (with "Float over text" unchecked).

\section{EXPERIMENTAL PROCEDURE}

\section{A. Material Selection}

Here the matrix alloy used in ZA-27 and its composition is given in Table1. 
TABLE1 Composition of ZA-27

\begin{tabular}{|c|c|}
\hline Aluminium & $26-28 \%$ \\
\hline Copper & $2-2.5 \%$ \\
\hline Magnesium & $0.01-0.02 \%$ \\
\hline Zinc & Balance \\
\hline
\end{tabular}

Titanium Dioxide, which is commercially available with size $50-80 \mu \mathrm{M}$ is used as reinforcement in the form of particulates.

\section{B. Preparation of composites}

The liquid metallurgy route using vortex technique [12] is employed to prepare the composites. A mechanical stirrer was used to create the vortex. The reinforcement material used was titanium dioxide particulates of size varying $50-80 \mu \mathrm{m}$. The weight percentage of titanium dioxide used was 2-6 weight percentages in steps $2 \%$. Addition of titanium dioxide in to the molten ZA-27 alloy melt was carried out by creating a vortex in the melt using a mechanical stainless steel stirrer coated with alumina (to prevent migration of ferrous ions from the stirrer material to the zinc alloy). The stirrer was rotated at a speed of $450 \mathrm{rpm}$ in order to create the necessary vortex. The titanium dioxide particles were pre heated to $200^{\circ} \mathrm{C}$ and added in to the vortex of liquid melt at a rate of $120 \mathrm{~g} / \mathrm{m}$. The composite melt was thoroughly stirred and subsequently degassed by passing nitrogen through the melt at a rate $2-31 / \mathrm{min}$ for three to four minutes. Castings were produced in permanent moulds.

\section{Specimen preparation}

Three point loaded specimens, typically flat strips of dimension $8 \mathrm{~mm}$ thickness, $40 \mathrm{~mm}$ wide and $150 \mathrm{~mm}$ long were prepared from the composites and the matrix alloy by adopting standard metallographic procedure for the stress

\section{Microstructure}

Before the corrosion test the matrix and composites are subjected to micro structural studies in order to show the equal distribution of reinforced titanium dioxide particulates. The following figures show the microstructures of matrix and composites.

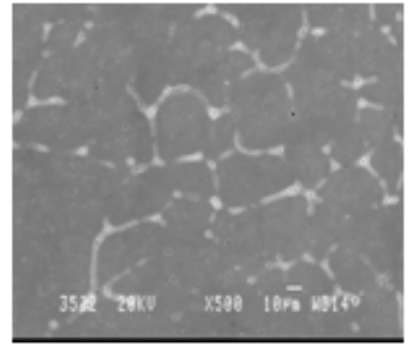

Fig.1 Microstructure of Matrix

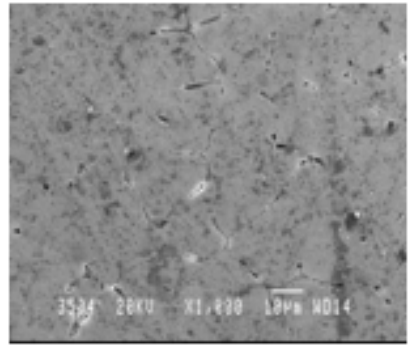

Fig. 2 Microstructure of $2 \% \mathrm{MMC}$
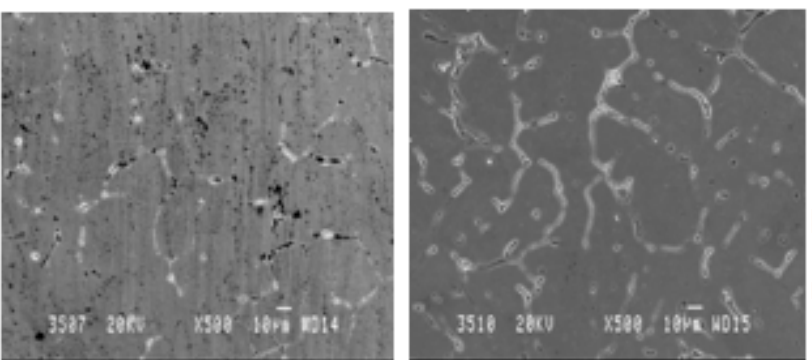

Fig.3 Microstructure of Fig.4 Microstructure of $4 \%$ MMC $\quad 6 \% \mathrm{MMC}$

Figures 1 to 4 show the microstructures of matrix and the composites taken from scanning electron microscope. In the microstructures of composites even distribution of titanium dioxide particulates is visible

\section{CORROSION STUDIES}

Autoclaves are often used for high temperature and pressure applications. The Teflon coatings protect the autoclaves from severe aggressive environments.

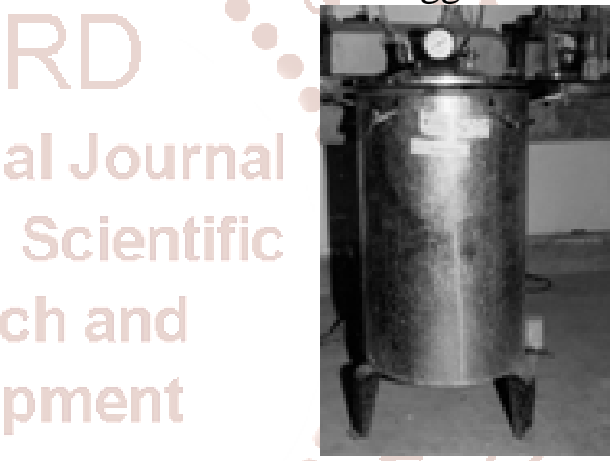

Fig. 5 Stainless steel autoclave

Figure 5 shows stainless steel autoclave. The specimen was supported at both ends and bending stress was applied using a screw equipped with a ball to bear against specimen at a point midway between the end supports. For calibration a prototype specimen of same dimensions were used and stressed to the same level. In a three point loaded specimen the maximum stress occurs at the mid-length of the specimen, decreases linearly to zero at the ends. The specimens were subjected to one third of matrix alloy's ultimate tensile strength. For each test two litres of different normalities of $\mathrm{HCl}$ solution, prepared were used. After loading the specimen in to the holder and placing the same in autoclave the required normality acid solution of 2 litres was added as corrodent. Then autoclave is closed and heated to test temperature with increase in inside pressure. Different composites with varying percentages of reinforcement were subjected to test at different temperature, different normality and corroded for 
various duration of $10,20,30,40,50$ and 60 minutes respectively. After the corrosion test the specimen was immersed in Clark's solution for 10 minutes and gently cleaned with a soft brush to remove adhered scales. Then after drying the specimens were accurately weighed again. Weight loss was calculated and converted to corrosion rate expressed in mils penetration per year (mpy) [14].

\section{RESULTS}

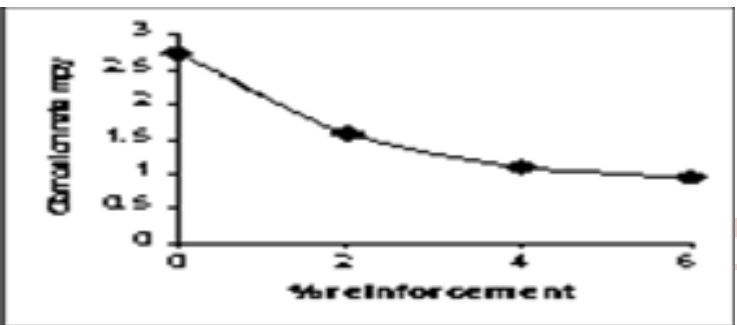

Fig. 6 Stress corrosion rates of MMCs in $1 \mathrm{~N} \mathrm{HCl}$ for 10 minutes exposure

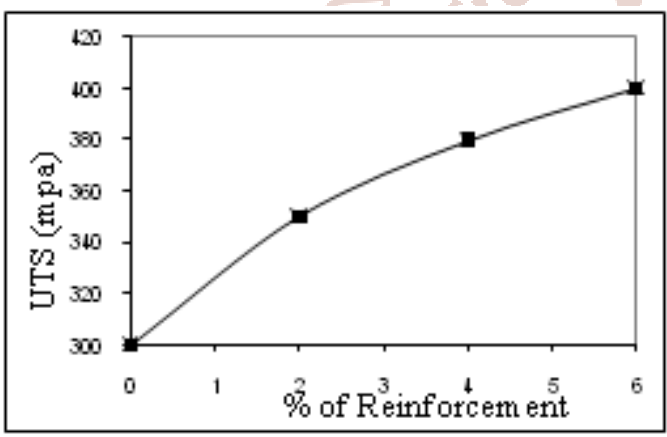

Fig. 7: Ultimate tensile strength of Matrix and MMCS in $1 \mathrm{~N} \mathrm{HCl}$

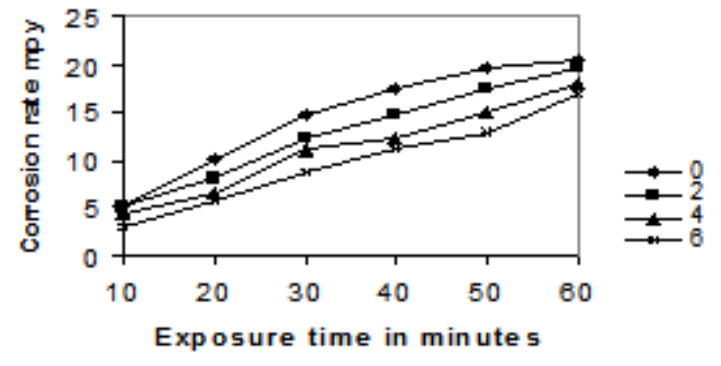

Fig. 8 Corrosion rate vs. exposure time in $1 \mathrm{~N} \mathrm{HCl}$ at $1000 \mathrm{C}$

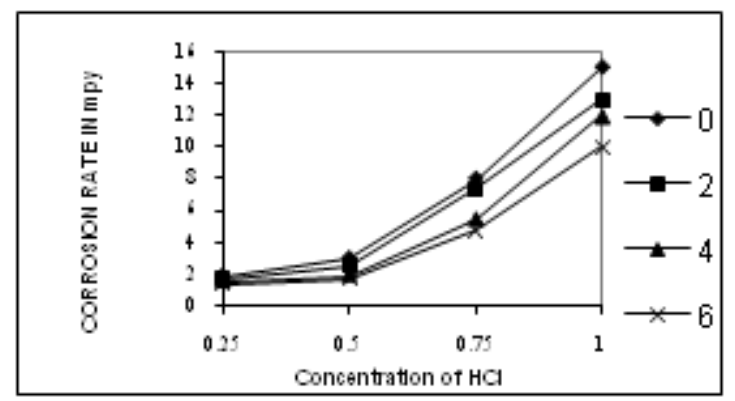

Fig. 9 Corrosion rate vs. concn. of $\mathrm{HCl}$ at $1000 \mathrm{C}$

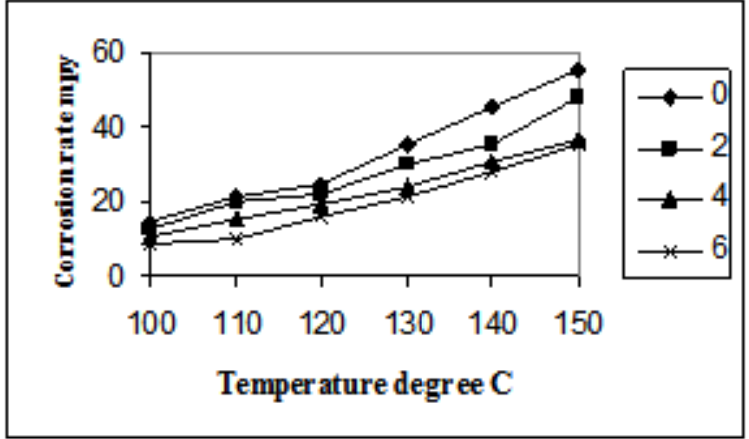

Fig. 10 Corrosion rate vs. exposure temperature

Figure 6 shows stress corrosion rate and Figure 7 shows the ultimate tensile strength vs. percentage of the titanium dioxide reinforced ZA-27 MMC's. The ultimate tensile strength increases with increase in the percentage of reinforcement with respect to matrix alloy [15]. Corrosion rate decreases with increase in the percentage of reinforcement with respect to matrix alloy [16]. Figure 8 shows stress corrosion rate vs. exposure time of ZA-27 and ZA-27/Titanium dioxide MMC's at $100{ }^{\circ} \mathrm{C}$ in $1 \mathrm{~N} \mathrm{HCl}$. The corrosion rates of both matrix alloy and composites increase with increase in exposure time.

Figure 9 shows the plot of stress corrosion rate vs. different concentrations of $\mathrm{HCl}$ at exposure temperature of $100^{\circ} \mathrm{C}$ and exposure time of 30 minutes. The stress corrosion rates of specimens increase with the concentration of $\mathrm{HCl}$. Figure 10 shows the stress corrosion rates of matrix alloy and composites in $1 \mathrm{~N} \mathrm{HCl}$ at different temperatures. All figures clearly show the decrease in corrosion rate monotonically with increase in titanium dioxide content. In other words greater the titanium dioxide particle addition, greater will be the corrosion resistance.

\section{CORROSIONMORPHOLOGY}

Specimens after stress corrosion test in $1 \mathrm{~N} \mathrm{HCl}$ solution for ten minutes exposure is subjected micro structural analysis using scanning electron microscope. The figures 11 to 14 show the microstructures of matrix and composites after stress corrosion test.

Visual examinations of the specimens after the stress corrosion experiments showed few deep pits, flakes and cracks formed on the unreinforced matrix alloy and the cracks were perpendicular to the axis of the specimen. Whereas more wide spread superficial pitting was observed and few or no cracks were seen on the surface of the reinforced composites. However 
few cracks on $2 \%$ titanium dioxide reinforced matrix composites and no cracks on $4 \%$ and $6 \%$ titanium dioxide reinforced matrix composites specimens were observed

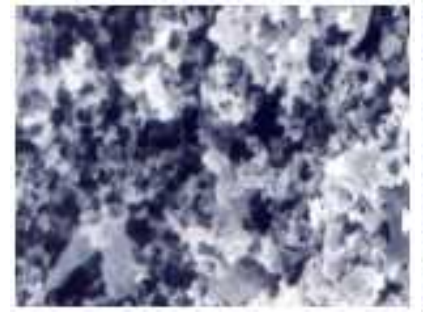

Fig.11 Microstructure of Matrix

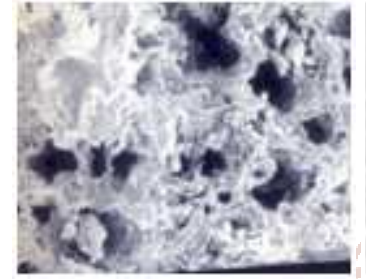

Fig.13 Microstructure of $4 \%$ composite

\section{DISCUSSION}

Hydrogen has been found to evolve when aluminium exposed to boiling water [17]. If the alloy alike ZA-27 is taken in acid solution like $\mathrm{HCl}$ then there will be liberation of hydrogen due to the slow dissolution of alloy. It may be due to the chemical reactions shown below.

$$
\begin{aligned}
& \mathrm{Zn}+2 \mathrm{HCl} \mathrm{ZnCl} 2+\mathrm{H} 2 \\
& \mathrm{Zn}+2 \mathrm{H} 2 \mathrm{O} \mathrm{Zn}(\mathrm{OH}) 2+\mathrm{H} 2 \\
& 2 \mathrm{Al}+6 \mathrm{HCl} 2 \mathrm{AlCl} 3+3 \mathrm{H} 2 \\
& 2 \mathrm{Al}+6 \mathrm{H} 2 \mathrm{O} 2 \mathrm{Al}(\mathrm{OH}) 3+3 \mathrm{H} 2
\end{aligned}
$$

The reaction rates for the above reactions are directly influenced by external variables such as exposure temperature of acidic solutions, exposure area of the specimen, concentration of hydrogen in solution, specimen exposure time and area of specimen exposed. Various researchers[18-19] have reported in their papers on static corrosion that the corrosion rate of the matrix alloy and the reinforced composites decrease with increase in exposure time. There may be possibility of conversion of hydroxide of aluminium into non-porous oxide layer, which prevents further corrosion. However the percentage of aluminium is only between $26-28 \%$. But in the case of Zinc, formation of oxide layer is ruled out. Hence the corrosion takes place and increases with increase in temperature, normality of $\mathrm{HCl}$ and exposure time.
Corrosion rates for matrix alloy and reinforced composites increased with increase in the normality of corrodent like $\mathrm{HCl}$. The corrosion rates in $1 \mathrm{~N} \mathrm{HCl}$ were more when compared to the corrosion rates in $0.25 \mathrm{~N} .0 .5 \mathrm{~N}$ and $0.75 \mathrm{~N} \mathrm{HCl}$ solutions. This is due to the increase in concentration of hydrogen in corrodant. Temperature also plays an important role in the corrosion properties. Two factors with respect to temperature, which influence on corrosion factors, are energy of activation of hydrogen ions and the temperature variation of hydrogen gradient. Titanium dioxide particles are inert and not expected to affect the corrosion mechanism of composites. The corrosion results indicate the improvement of corrosion resistance as the percentage of titanium dioxide increased in the composites. This shows the direct or indirect influence of titanium dioxide particles on the corrosion properties of the composites. Several authors [20-22] point out that the extent of pitting in SiC-ZA-27 MMC increased with increase in $\mathrm{SiC}$ volume fraction which may be due to the preferential acidic attack at the matrix reinforcement interface [23]. The corrosion behavior of MMCs is influenced by the nature of matrix alloy, type of reinforcement and alloying elements [24], in spite of these factors the corrosion behaviour in ZA27 MMCs is a complex nature [25]. But nature of bond between reinforcement and matrix plays an important role in the corrosion property. Since the composites developed show improved mechanical properties it can be claimed that the interface between the matrix alloy and reinforcement is quite strong[26]. To support this it was observed that when titanium dioxide particle content is increased there is a reduction in corrosion.

\section{CONCLUSION}

Corrosion rate increases with solution temperature. Titanium dioxide is a ceramic material and hence not involved in galvanic corrosion with matrix alloy. Normality of $\mathrm{HCl}$ plays significant role in the corrosion of ZA-27/Titanium dioxide MMC's. The increase in hydrogen evolution results in higher corrosion rate. Corrosion rate increases with increase in time of exposure and temperature. The extent of corrosion damage was reduced with increasing reinforcement. Which may be due to increase in tensile strength and bonding strength of the MMCs. Material loss from corrosion was significantly higher in case of ZA-27 than in the ZA-27/Titanium dioxide MMCs 
International Journal of Trend in Scientific Research and Development (IJTSRD) ISSN: 2456-6470

\section{REFERENCES}

1. Seah K.H.W., Rao P. R. and Girish B. M., Material \& Design Vol.16, pp 277- 1995

2. Girish B.M., Rathnakar Kamath and Sathish B.M., Wear, vol. 219 pp 162- 1998

3. Keith R Karasek, and Bevk, J. Appl. Phys, vol. 53, pp 1370- 1981

4. Joseph E Bishop and Vikraam. K. Kinra, Metall. Trans. A, vol. 26A, pp 2773 - 1995

5. Pohlman S.L, Corrosion, vol. 34, pp136 1978

6. Koya E., Hagiwara Y., Miyura S, Hayashi T., Fujiwara T and Onoda M., Soc. Automotive Engrs. Inc., pp55-64, 1994

7. Aghajanian M. K. AtlandG. C. Barron P Antolin and. Nagelberg A.S, Metal Matrix Composites, Soc. Automotive Engrs. Inc., pp73-81 1994

8. Trazakoma, P.P., Corrosion, pp46- 1990

9. Paciez R. C and Agarwala V S, Corrosion, vol. 42, pp 718- 1986

10. Sun H. Koo E.Y and. Wheat H.G, Corrosion, vol. 47, pp 741- 1991

11. AylorD. M. and Moran P.J., J. Electrochem. Soc vol. 132, pp277-1985

12. Hihara L. H and. Latanision R.M, Int. Met. Rev. vol. 39 pp245- 1994
13. Nutt S.R, Treatise Mat. Sc. Technol.

14. Seah K. H. W, Hemanth J, Mater. Design. vol.15(3), pp 299-304 1994

15. Krupakara P.V, Oct 9-12,2000 Proceedings of "Material solution conference" ASM, USA

16. Krupakara P.V, Proceedings of Nov5-8,2000, "Processing materials for properties 2000" TMS, USA

17. Roberts W, "Deformation processing and Structure". (Ed) G. Krauss, 1984ASM Metals. Park. OH., 109-184

18. Seah K.H.W,. Girish B.M and Venkatesh, J Corrosion Sc.vol.39(8), pp 1443-1449 1997

19. Seah K. H. W. Girish B.M , Corrosion Sc. Vol.39(1), pp 1-7 1997

20. Trazakoma, P.P., Corrosion, vol. 46, pp 1990

21. Paciez R.C and Agarwala V S, Corrosion vol.42, pp 718- 1986

22. Sun H, Koo E. Y. and.Wheat H.G, Corrosion, vol. 47, pp 741- 1991

23. Aylor D. M and. Moran P.J, J. Electrochem. Soc vol.132, pp 12771985

24. HiharaL. H. and. Latanision R. M, Int. Met. Rev. vol. 39 pp 245- ,1994

25. Nutt. Treatise, Mat. Sc. Technol. 313891989 